\title{
Outbreak of Campbell de Morgan Spots*
}

\author{
R. H. SEVILLE, $†$ M.D., M.R.C.P. ; P. S. RAO, $\ddagger$ M.B., B.S., B.SC. ; D. N. HUTCHINSON, $\$ M.B., CH.B., DIP.BACT. \\ G. BIRCHALL, $\|$ M.B., CH.B., M.R.C.PATH.
}

\begin{abstract}
Cummary: An outbreak of small angiomatous lesions $\checkmark$ with the same clinical and histological features as Campbell de Morgan spots in adults is described. No infective agent was discovered, but their number was found to increase as the ambient temperature rose.
\end{abstract}

\section{Present Investigation}

On 2 June 1968 an outbreak of Campbell de Morgan spots was discovered in Lancaster Moor Hospital. Within a few days cases were seen at other local hospitals, and eventually over 1,000 patients were affected. The spots appeared suddenly and in large numbers and were not associated with any systemic upset. Older patients with previously existing spots reported that new ones had developed.

The lesions started as bunches of vascular loops, 0.5 to 4 $\mathrm{mm}$. in diameter, and were roundish or irregular in shape, with a uniform or lobulated surface. They did not vary in size from day to day. In about a week they changed in colour from arterial red to cherry red, and later to venous red as they became more homogeneous. They did not fade on dioscopy, and there was no purpura. The lesions were distributed mainly on the trunk, upper limbs, and thighs.

Spots smaller than $1 \mathrm{~mm}$. tended to disappear in one to two weeks. An early sign of resolution was the development of a homogeneous appearance, when the identity of the capillary loops was lost; rarely a few loops remained, some of which disappeared within a further week, but others were still present six months later. Occasionally the whole lesion thrombosed, darkened, and then disappeared. Lesions over $2 \mathrm{~mm}$. in diameter tended to remain. The edges became more regular, the texture appeared more firm, and the colour became darker and more uniform. Histologically the lesions were Campbell de Morgan spots as explained in detail later.

One patient (a woman aged 33) showed interesting features in that she gave a history of recurrent attacks of the lesions. These occurred every spring since she came to live in Arnside 10 years ago. The lesions usually stayed until cooler weather was experienced in September. They disappeared if the summer was cool, only to erupt again if the autumn was hot. Two colleagues had noticed that they developed typical lesions a day or two after exposure to hot sun.

The weather during the week before the outbreak was unusually warm, and followed a particularly cold period. We observed nine dermatological inpatients. All lesions visible to the naked eye were counted three times a week from June to August. Eighteen geriatric and 40 mentally subnormal

\footnotetext{
* Presented to the North of England Dermatological Society on 18 June 1968.

+ Consultant Dermatologist, Beaumont Hospital, Lancaster.

¥ Registrar in Dermatology, Derbyshire Royal Infirmary, Derby; Formerly Senior House Officer in Dermatology, Beaumont Hospital, Lancaster. Consultant Bacteriologist, Preston and Chorley Hospitals.

|| Consultant Pathologist, Royal Lancaster Infirmary.
}

inpatients were then observed from August to November for three months, the counts being fortnightly. One of us (P.S.R.) was responsible for all the counting. The figures were compared with readings of the maximum daily air temperature.

\section{Results}

An increase in the number of spots occurred as the temperature rose. This is seen in the Chart, where the number of

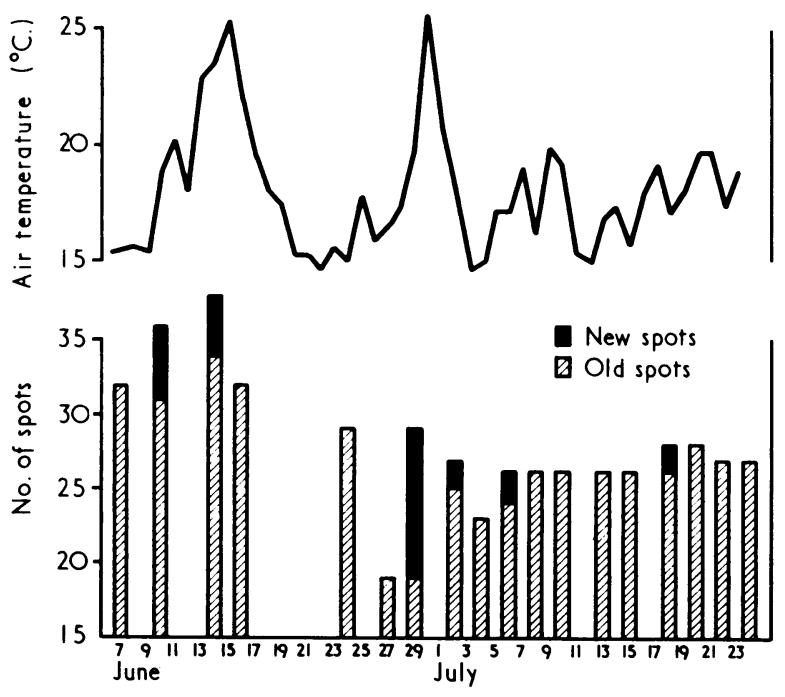

Diagram illustrating the variation of total count of Campbell de Morgan spots with the external temperature in one patient.

spots counted in one patient is shown against the ambient temperature. This phenomenon was observed in eight of the nine skin inpatients.

A decline in the number of lesions with the onset of colder weather was noted in 19 of the $\mathbf{4 0}$ mentally subnormal and in half the geriatric patients. The decline was halted when the central heating was adujsted early in October.

\section{Laboratory Investigations}

Typical lesions which had been observed for periods of between two days and four months were excised. Histological examination showed no unexpected features. The larger lesions had appearances identical with the descriptions of Campbell de Morgan spots (cherry angioma) by Lever (1967). They were indistinguishable from lesions which had been removed, both during the present outbreak and in previous years, as typical Campbell de Morgan spots. These were collections of capillaries, some dilated, in the upper dermis. They showed a scattered infiltrate of lymphocytes and histiocytes, and were 
covered by epidermis which was normal, except where stretched over a raised lesion. The smaller spots consisted of a few dilated capillaries in the subepidermal region, again with a scanty lymphocytic infiltrate, and were similar to the lesions described by Brannen et al. (1961), though we were not able to demonstrate the decrease of elastic tissue found by those authors in some of their specimens.

Numerous tests were carried out to exclude infective or systemic causes, virtually all giving negative results.

A number of the early cases were investigated haematologically, the tests including haemoglobin levels, counts of white cells and platelets, examination of peripheral blood films, estimation of erythrocyte sedimentation rates, tests of capillary fragility (Hess), and estimations of the bleedingtime and clotting-time. No consistent unexpected findings were made. In six patients the blood counts were repeated on three successive weeks.

Serial liver function tests were made on the same six patients, The total bile pigment, thymol turbidity, zinc sulphate turbidity, and serum alanine aminotransferase results were within normal limits. The serum alkaline phosphatase levels were high (average 26 units $/ 100 \mathrm{ml}$; normal 3 to 12 units) in the first week, falling in the second and third weeks (17 and 12 units $/ 100 \mathrm{ml}$. respectively). The significance of this finding is not apparent to us. Various biochemical tests carried out on other affected patients yielded no unexpected results.

Representative samples of meals were no longer available, but many food ingredients supplied in common to all the affected hospitals were obtained, together with new batches of meat and other perishables. Bacterial counts and routine cultures were made of all specimens, but no recognized pathogen was found. Microscopy for protozoa and culture for foodpoisoning organisms of 20 faecal specimens showed no common agent.

Detailed virological investigations were undertaken on six patients; from each we collected throat washings within 48 hours of onset of the lesions, blood at the onset and three weeks later, three samples of urine at weekly intervals, and three specimens of faeces. Lesion biopsy specimens were taken from two patients. We also examined blood, thoat washings, urine, and faeces collected at random from several other patients.

Throat washings, urine, and extracts of food, faeces, and biopsy tissue were inoculated on to secondary rhesus monkey kidney, human amnion, human fibroblast, and HeLa cells grown and maintained by recognized techniques. Subcultures were made at weekly intervals, and the primary inoculated tube material was passaged three times at fortnightly intervals. No cytopathic or haemadsorbing agent was detected. Interference was not investigated. Pools of throat washings and of faecal extracts were inoculated intracerebrally into suckling and young adult white mice. After three weeks the animals were killed, the brains emulsified, and further mice inoculated. The animals remained well and no macroscopic lesions wereobserved at necropsy. The paired sera showed no complement-fixing antibodies to common respiratory viruses. No virus particles were seen on electron microscopy of one biopsy specimen.

\section{Discussion}

The initial events raised the question of whether there was any valid field epidemiology. The major incidence within the same week in the semiclosed communities of various hospitals in the same hospital group focused investigation on any common infective or toxicological factors. Each had different water supplies, milk sources, and laundries, but all shared some common food supply channels for many items of diet. Yet the scrutiny of diet sheets and the microbiological examination of a wide range of foods yielded no clue. Bacon was specially analysed because of the possible use of hexoestrol or other steroids for bringing animals more speedily to marketable size, but no oestrogens were found. There was no correlation with the seasonal use of chemical herbicides and pesticides in the hospital grounds.

The possibility of person-to-person infection seemed unconvincing because of the pattern of concurrent incidence within separate hospitals, and there was no evidence to point to animal or insect vectors.

Fifty-seven adult dermatological inpatients in Liverpool were examined on 11 June and 47 in London on 13 June. The findings in Liverpool were similar to those in the chest, dermatology, and general medical wards at Lancaster, but in London the lesions were fewer. The change in ambient temperature was pronounced at the end of May in the NorthWest of England, whereas in the South-East, though 1 to $7^{\circ} \mathrm{C}$. warmer, the change was more gradual and of less extent. It has already been noted that the spot count increased after rises in temperature and fell with the onset of cold weather. It is suggested that the differences in geographical counts were due to the different temperature changes encountered.

Thirty paediatric patients aged 5 to 13 years at Lancaster, Liverpool, and London were also examined, but none was affected. Bean (1953) recorded similar findings. Brannen $e t$ al. (1961) described lesions which had the same distribution, clinical and histological appearance, and close association with Campbell de Morgan spots.

It was also noted that occasionally the whole lesion thrombosed, darkened, and disappeared. Parkes Weber (1947) described similar involution in Campbell de Morgan spots. None of the references quoted in this article mentioned an eruptive onset or any associated systemic upset.

After a study of nearly 1,000 patients Bean (1953) concluded that the opinion of Campbell de Morgan (1872), that the lesions were the hall-mark of cancer, was incorrect. The description and distribution in Bean's article fits exactly the lesions we have seen; there was the same bright cherry-red colour, elevation of the larger lesions a few millimetres above the skin, and magnification showing "numerous vascular loops, discrete and easily identified at the periphery, jumbled together at the centre," and also revealing smaller lesions almost invisible to the naked eye.

We wish to thank Dr. F. T. Madge for his invaluable assistance in the presentation of this material. We are very grateful to Dr. S. Smith, Dr. E. H. Wilson, and Dr. R. C. Cunningham, of Lancaster, to Dr. C. McGibbon, of Liverpool, and to the consultant staff of St. John's Hospital, London, for allowing us to examine their patients; to Dr. J. Nagington, of Cambridge, for electronmicroscopic investigation; to Dr. Bridie Wilson and Mrs. S. Barber for the detailed analysis and chart; and to the University of Lancaster and Mr. R. O. Seville for the weather records.

\section{REFERENCES}

Bean, W. B. (1953). Transactions of the Association of American Physicians, 66, 240.

Brannen, M., Nixon, R. K., Doucette, J. W., and Fosnaugh, R. P. (1961). Archives of Dermatology, 83, 386.

De Morgan, C. (1872). The Origin of Cancer, p. 16. London, Churchill.

Lever, W. F. (1967). Histopathology of the Skin, 4th ed. London, Pitman Medical.

Weber, F. P. (1947). Rare Diseases and Some Debatable Subjects, 2nd ed., p. 51. London, Staples Press. 